\title{
FOSTERING CREATIVITY IN DESIGN - AN EMPIRICAL STUDY ON IMPROVEMENT OF REQUIREMENT- SATISFACTION WITH INTRODUCTION OF INDEATE TOOL
}

\author{
Acharya, Shakuntala (1); Bhatt, Apoorv Naresh (1); Chakrabarti, Amaresh (1); Nagai, Yukari (2) \\ 1: Indian Institute of Science Bangalore; 2: Japan Advanced Institute of Science and Technology
}

\begin{abstract}
In today's highly competitive market, product success is determined by two critical factors - innovation and sustainability. While innovation looks to rampantly satisfy the consumers' ever growing requirements with creative solutions, sustainability attempts to rationalise the precarious demands of desired requirements on economy, society and environment.

InDeaTe - Innovation Design database and Template, a web-based, design process guidance tool, supports design of sustainable systems by incorporating sustainability requirements into the design process. This paper investigates the potential of the tool to improve the usefulness of a design, one of the indicators of the creativity of the solutions, apart from its novelty. Comparative studies are conducted to assess the improvement of 'requirement-satisfaction', a proxy measure for usefulness. Upon introduction of the tool into the design process, significant improvements are reported, thereby reflecting the ability of InDeaTe to increase the usefulness of solutions and foster creativity in design.
\end{abstract}

Keywords: Sustainability, Creativity, Conceptual design

Contact:

Acharya, Shakuntala

Indian Institute of Science Bangalore

Centre for Product Design and Manufacturing

India

shakuntala.acharya@icloud.com

Cite this article: Acharya, S., Bhatt, A.N., Chakrabarti, A., Nagai, Y. (2019) 'Fostering Creativity in Design - An

Empirical Study on Improvement of Requirement-satisfaction with Introduction of InDeaTe Tool', in Proceedings of the 22nd International Conference on Engineering Design (ICED19), Delft, The Netherlands, 5-8 August 2019. DOI: $10.1017 /$ dsi.2019.370 


\section{INTRODUCTION}

Innovation and sustainability and are two key factors determining product success in today's rapidly changing, highly competitive, consumerist world. On one hand, while users crave for the new and the exciting, there is also a growing appreciation for the need of incorporating sustainability towards a more promising future. Sustainability, as an ideology, has its roots in the Brundtland Report that wove social, economic, cultural and environmental issues, and global solutions together (WCED, 1987: p43). However, sustainable solutions might not necessarily be innovative, and vice versa. While "creative solutions cause innovation in all design areas" (Eder, 1995), of all the creative ideas generated during the design process, only a small number end up as innovation (Cavallucci, 2002). The potential degree of creativity of a solution may be gauged during the design process by assessing the indicators of creativity, namely, 'novelty' (Shah, et al., 2003; Sarkar \& Chakrabarti, 2007, 2011) and 'usefulness' (Lozano, 2009; Sarkar \& Chakrabarti, 2007, 2011; Srinivasan \& Chakrabarti, 2010).

InDeaTe - Innovation Design database and Template is a web-based, design process guidance tool (Chakrabarti, et al., 2017, Acharya, et al., 2018) that fosters innovation by imbibing life cycle thinking into the design process and improving sustainability considerations during design. However, a question remains as to whether this necessarily implies that the designs created are creative, so that the overall likelihood for sustainable innovation is improved. To assess the creativity of a design during the design process, Ranjan, et al. (2018) propose, along with the use of 'novelty', 'degree of requirement-satisfaction' or DRS, the latter as a proxy measure for 'usefulness' - a creativity indicator - before the product is developed and taken to the society. However, at the conceptual stage of design, evaluating 'usefulness' or DRS is challenging as solutions exist at different levels of abstraction, lacking physical manifestation. But it is also the stage where the greatest flexibility to incorporate change, i.e., improve the design by increasing the sustainability of requirements (and solutions) and the intent to satisfy such requirements, is feasible. Therefore, supporting this intended 'requirement satisfaction' by a solution, through appropriate generation and selection of sustainable requirements, shows the potential usefulness of that conceptual solution.

The goal of the collaborative research presented in this paper is to investigate, through comparative design studies, the capability of the InDeaTe tool for its improvement in supporting sustainable design innovations. The objective of this paper is to evaluate the 'potential usefulness' of the design - as an indicator of the creativity of the solutions produced with support of the tool. This paper examines the influence of InDeaTe on, the number of sustainable requirements (and solutions), as well as, on the intended 'requirement-satisfaction', indicated by the selection of as many sustainable requirements possible that can be satisfied by the conceptual solution proposed.

\section{LITERATURE REVIEW}

\subsection{InDeaTe tool: Supporting sustainable design}

'Life cycle thinking' (EPA, 1993; Vezzoli \& Manzini, 2008), is a strategy towards sustainable design. It encourages the consideration of all life cycle phases of a design, namely material extraction, production, transport/distribution, use, and after-use. This approach aids in assessing and incorporating sustainability considerations into design, through indicators, indices and standards, such as Ford Product Sustainability Index (Schmidt \&Taylor, 2006) and Sustainability Standards protocol (NIST, 2010). These indicators, in turn, are scoped within the three pillars of sustainability, i.e., society, economy and environment, termed as the Triple Bottom Line or TBL scope (Elkington,1997). With over 80 definitions of sustainability that are widely accepted and used, such as WCED (1987), IISD (Bossel, 1999), and OECD Paris (Strange \& Bayley, 2008), the incorporation of sustainability considerations into a design greatly depends on the interpretation and scope of the definition of sustainability adhered to by the designer.

As part of its support, InDeaTe provides information on sustainability definitions and pertinent indicators, along with appropriate design methods and tools, for use at each design stage, activity and life cycle phase of the system being designed. The tool was previously assessed for (i) its support to improve sustainability 
considerations and (ii) its effectiveness in the design process. The results obtained from six case studies conducted to test the above (Devadula, et al., 2017; Ghadge, et al., 2017a; Ghadge, et al., 2017b; Acharya, et al., 2017a; Acharya, et al., 2017b; Uchil, et al., 2017) were positive: use of the tool helped systematically imbibe sustainability considerations into the design process and its outcomes.

\subsection{Description of InDeaTe tool and template: Ontological background}

InDeaTe tool (Chakrabarti, et al., 2017, Acharya, et al., 2018), comprises a design process Template and a design Database; it supports the designer by providing suitable sustainability related information, i.e.,

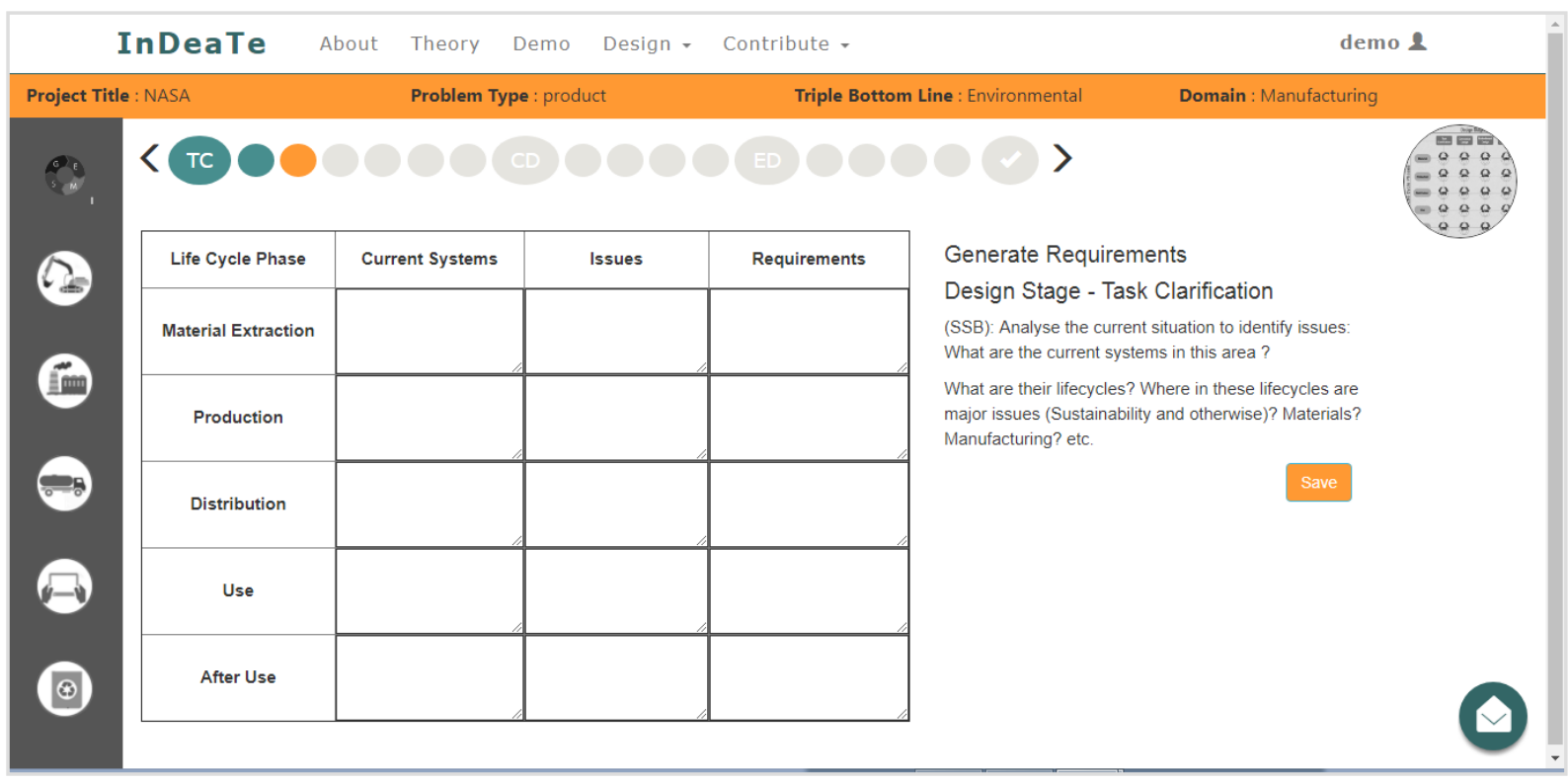

Figure 1. InDeaTe web-tool: Imbibing lifecycle thinking into requirements generation

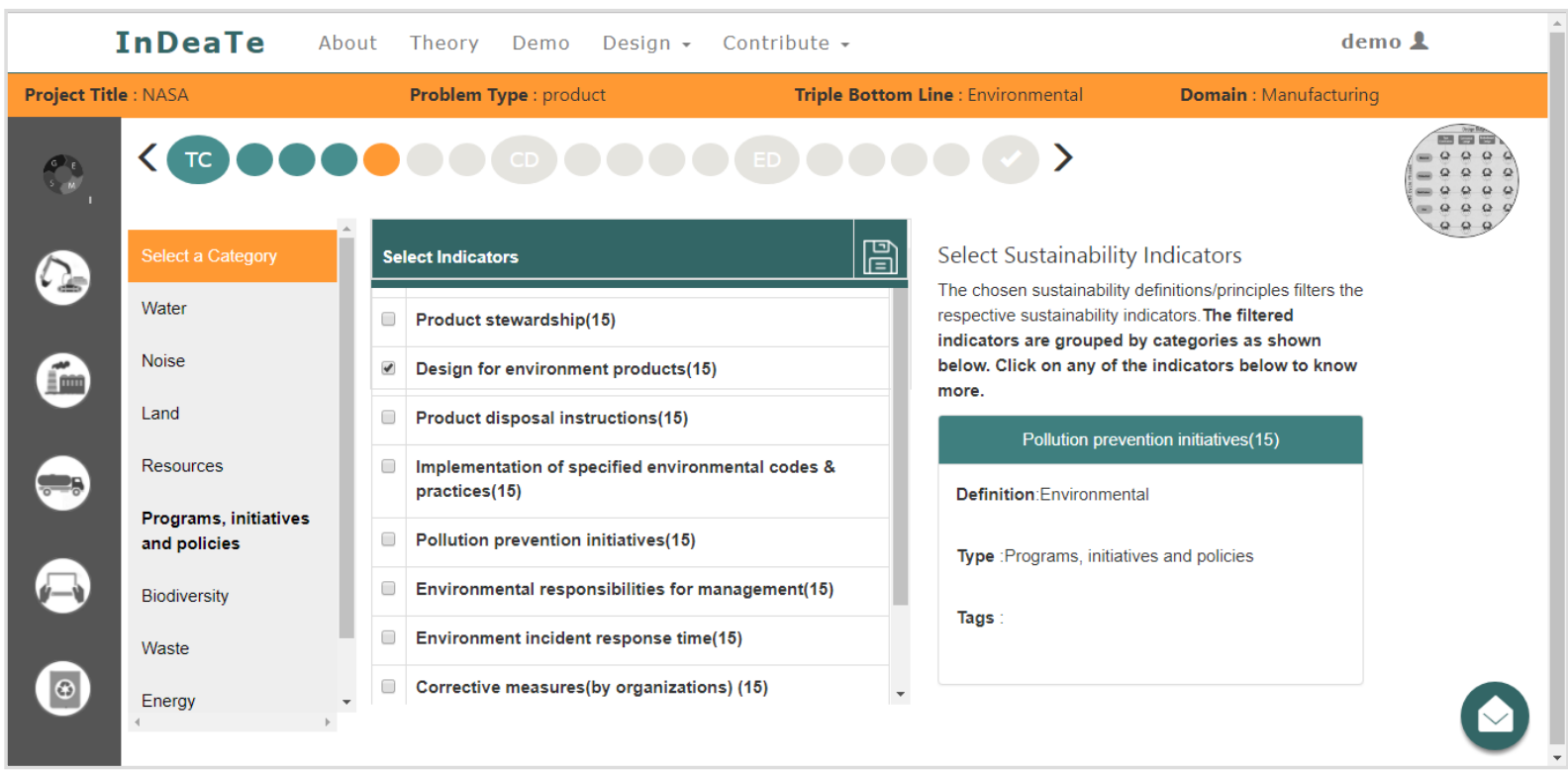

Figure 2. InDeaTe web-tool: Supporting knowledge and incorporation of sustainability indicators to iteratively improve List of Requirements (LoR)

sustainability definitions and indicators, and pertinent design methods and tools appropriate for use at each design stage, via a web-based, user-friendly graphical interface (Acharya, et al., 2018). The Template guides the designer, step-by-step in each design stage, to perform iterative activities of design, 
i.e., generate-evaluate-modify-select or GEMS (Srinivasan \& Chakrabarti, 2010) considering the effect on each life cycle phase of the outcomes of the design, i.e., requirements and solutions, illustrated in Figure 1. The Database is ontologically tagged using the dimensions of ACLODS - Activities, Criteria, Life cycle phase, Outcome, Design Stage and Structure - that were found to be important, for life cycle development of a design, based on empirical and theoretical studies (Kota and Chakrabarti, 2014).

The InDeaTe tool supports the designer to select appropriate sustainability indicators, as in Figure 2, and use these to iteratively generate-evaluate-modify and select requirements, and incrementally improve the List of Requirements (LoR). From this list, requirements are selected and addressed to generate solutions, or requirements are evaluated against to modify and/or select the most satisfactory solution amongst its several variants. The LoR is used as the benchmark during design to evaluate each solution with respect to the requirements selected for that solution.

\subsection{Requirement satisfaction - A creativity indicator of a design}

Oman, et al. (2013) define innovation as "creativity that embodies usefulness in order to realise an impact on society (i.e., application of said creativity) through a new method, idea, or product". To assess creativity of a design, the main indicators are 'novelty' which entails the new, original and unusual, and 'usefulness' which encompasses appropriateness, purpose, meaning, value and satisfaction (Sarkar and Chakrabarti, 2007, 2015; Howard et al., 2008). Novelty is often measured subjectively, mostly by comparison to existing products or idea spaces (Shah, et al., 2003; Sarkar and Chakrabarti, 2007; Peeters et al., 2010; Lopez-Mesa et al., 2011). Usefulness of a design can truly be assessed only post-development, from the consumer experience of the product in its use-phase (Moss Jr, 1966; Sarkar and Chakrabarti, 2007). However, during the design process, it can be estimated by the 'requirement-accomplishment' evaluated against requirements (Lozano, 2009) or by the 'degree of requirement-satisfaction' i.e., DRS (Ranjan, et al., 2018).

At the conceptual stage, it is difficult to assess the DRS across a scale as the solution is not welldefined with a structure having geometric and material properties. Therefore, in this work, the potential usefulness of a conceptual solution indicated by the intended requirement-satisfaction is evaluated (using 0 or 1 , where 1 is taken if the requirement is satisfied, and 0 if not). It is calculated as the 'number of requirements selected' (R-S), with the intent to satisfy as many 'requirements generated' (R-G) as possible, while conceptualising the solution.

\section{EMPIRICAL STUDY}

The underlying hypothesis of the comparative study tested in this paper is the following: "The use of InDeaTe supports improvement of the degree of requirement-satisfaction (DRS) of the designs produced using InDeaTe". Since DRS can be used as a proxy measure for usefulness of a design, and usefulness is an indicator of creativity (Ranjan, et al., 2018); testing of the above hypothesis should be an indirect corroboration of the influence of InDeaTe in supporting creativity and associated innovation. The proposed empirical study tests the effect of the tool, already known for increasing sustainability considerations into the design process, on improving the requirement satisfaction in a solution, with respect to sustainability requirements (Rs) and non-sustainability requirements (Rns).

\subsection{Experimental protocol}

The study comprised two design sessions; the following is an overview of the experimental set up:

- Design Session: Involved designing of a product as per the problem brief without the aid of the InDeaTe tool in Session 1, and then with the use of the tool and template in Session 2. An introductory session on the theory and use of the tool was given at the start of Session 2.

- Problem brief: "Design an easy to clean, easy to carry and multi-use cutlery. (spoon, fork, knife, chopsticks-all products used to eat food is cutlery)"

- Design Methodology: The design methodology followed for this study is as per the InDeaTe design process Template (Table 1), where iterative GEMS activities of design are performed in every design stage while considering each life cycle phase of design. 
- Design support/tool: InDeaTe - Design process Template and Design Database. (Note - designers had access to only the sustainability part of the Design Database and not the design methods and tools part, due to paucity of time and language barriers in these cross-cultural design sessions).

- Duration: 3 hours for each design session

- $\quad$ Stages of Design: Task Clarification and Conceptual Design.

- Deliverables: Iterative 'List of Requirements' (LoR) - preliminary and final, conceptual sketches of solutions, with selection of one solution as the final concept.

- Participants : 6 teams, each with 2 individuals having or currently pursuing post-graduate degrees in science or engineering. The teams were formed on the basis of familiarity of language and cultural backgrounds nationalities. Participants hailed from Japan, India, Bangladesh and China.

Team 1: Indian Subcontinent, 1 female and 1 male

Team 2: Japanese, 2 males

Team 3: Japanese, 2 males

Team 4: Chinese, 2 females

Team 5: Chinese, 1 female and 1 male

Team 6: Chinese, 1 female and 1 mal

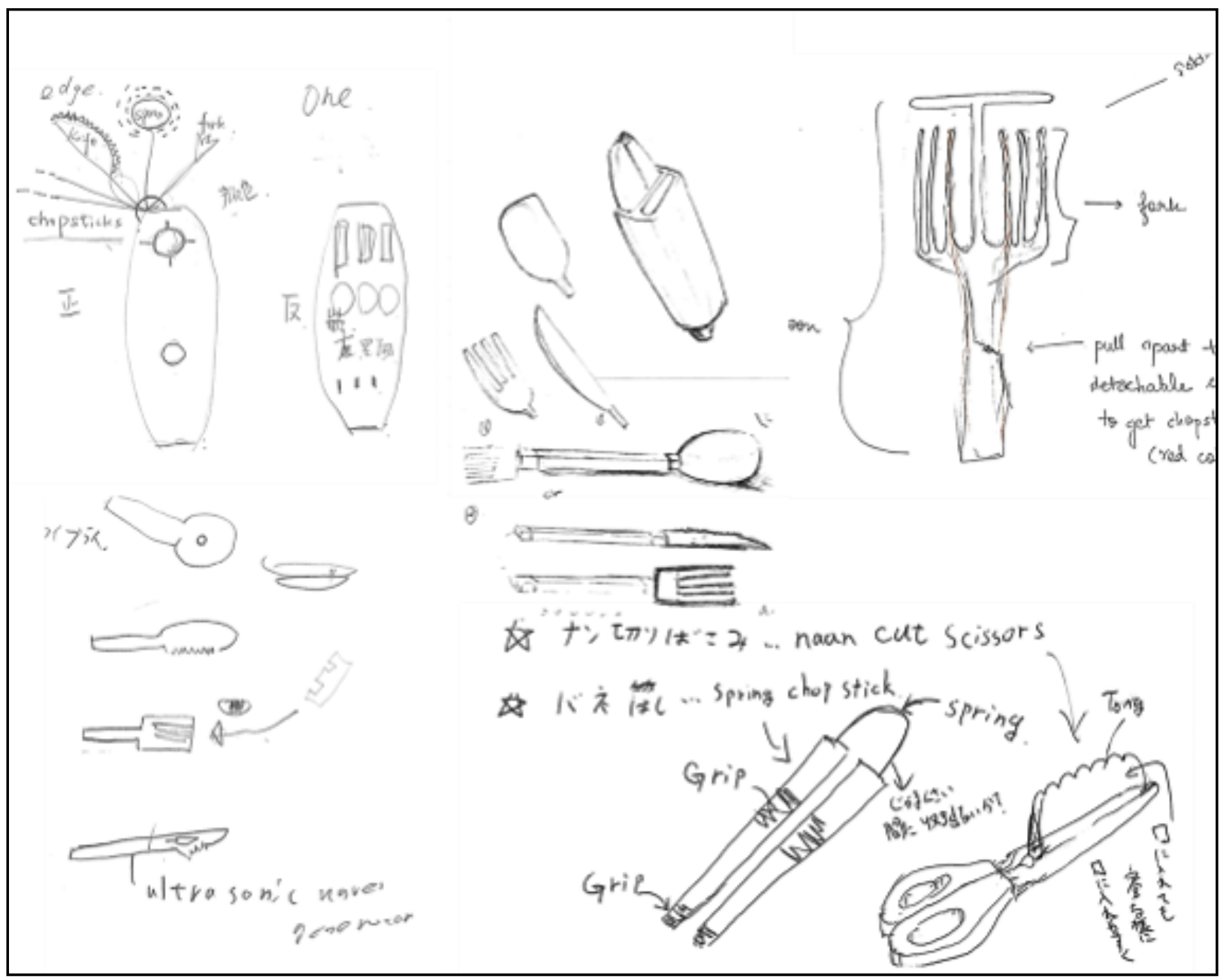

Figure 3. Design data in form of concept sketches with labels/text

This is a collation of several conceptual sketches made by the teams, to give an overview of the data from the design exercises.

In one, the team explores several solution-variants of spoon, fork, knife, chopsticks - with and without a flexible spring, pizza cutter and a scissor-like tong; within the umbrella concept of fitting one or more of these into an easy to carry, hand-sized case with buttons to activate the opening of the needed cutlery. Another team also explores different ways in which the cutlery will come out and be packed back into a case. Another unique solution was a single piece of cutlery (top right corner) that could be oriented and taken apart to become several different pieces. 


\subsection{Methodology for assessment}

The below mentioned assessment methodology was followed, to assess the capability of the Tool:

- Unit for analysis: One design solution, selected as concept by each team, is analysed as a unit.

- Data for analysis: The data is in the form of iterative Lists of Requirements, design sketches with label or description in text.

- Coding of data: Requirements from the LoR and from the concept sketch are tabulated and coded by expert/researcher with respect to;

- sustainability requirements (Rs) and non-sustainability requirements (Rns), and

- requirement generated (R-G), i.e., all those enlisted by designer, and requirement selected (RS), i.e., only those incorporated in the solution during conceptualisation.

- $\quad$ Criterion for the assessment of the design;

- increase in sustainability consideration, i.e., increase in the number of sustainability requirements generated (Rs-G). This is calculated as, percentage of increase in R-S with use of tool with respect to R-G = additional (R-S) / (R-G).

- improvement in requirement satisfaction, i.e., increase in the number of sustainability requirements selected to be satisfied (Rs-S).

Therefore, DRS is calculated as, the percentage increase in requirement selection, i.e., percentage of additional requirements selected (R-S) upon use of tool with respect to the total number of requirements generated $(\mathrm{R}-\mathrm{G})$.

- Methodology of assessment: The no. of requirements (sustainable and non-sustainable) generated (R-G), and no. of requirements (sustainable and non-sustainable) selected (R-S) and \% increase in the requirements selected to requirements generated for each solution, with the additional use of the tool are benchmarked against those without the use of the tool and noted under 'increase in sustainability consideration' and 'improvement in requirement satisfaction', respectively.

\subsection{Results}

An example of the design outcome or experimental data, in the form of text description and sketches of selected concepts by the different teams, analyzed is given in Figure 3. An example of coding the data after consolidating the LoR, by adding requirements missed in the list but present in the sketches, is elucidated in Table 1.

Table 1. An example of coding the design data (T6)

\begin{tabular}{|c|c|c|c|}
\hline $\begin{array}{l}\text { Design } \\
\text { Session }\end{array}$ & Requirements Generated (R-G) from LoR & $\begin{array}{c}\text { Sustainable } \\
\text { (Rs) / Non- } \\
\text { sustainable } \\
\quad \text { (Rns) }\end{array}$ & $\begin{array}{l}\text { Requirements } \\
\text { Selected (R-S) }\end{array}$ \\
\hline \multirow{5}{*}{$\begin{array}{r}\text { Session } 1 \\
\text { Without } \\
\text { Tool }\end{array}$} & Spoon doesn't reach at the corner of box/ dish & Rns & Yes \\
\hline & fork and knife is too sharp, may hurt person & Rns & Yes \\
\hline & fork-hard to clean & Rns & No \\
\hline & cannot use knife with one hand & Rns & No \\
\hline & chopstick-easy to chop and easy to lose & Rns & No \\
\hline \multirow{7}{*}{$\begin{array}{r}\text { Session } 2 \\
\text { With } \\
\text { InDeaTe } \\
\text { Tool and } \\
\text { Template }\end{array}$} & material should be cheap and healthy & Rs & Yes \\
\hline & cutlery should be high temperature resistance & Rns & Yes \\
\hline & it should be chemically itching resistant & Rs & Yes \\
\hline & $\begin{array}{r}\text { Manufacturing process should be easy (to get desired } \\
\text { shape), easy to assemble, less components }\end{array}$ & Rs & No \\
\hline & manufacturing cost should be less & Rs & No \\
\hline & packaging in different part saves more space & Rs & Yes \\
\hline & recycling in different parts & Rs & Yes \\
\hline
\end{tabular}




\subsection{Observations}

The results of analysis of the coded data from the study (without tool and with addition of tool) are given in Table 2. The main observations from the comparative study, based on the data from the six teams, are as follows:

- The use of the tool resulted in first-time incorporation of sustainability consideration: generation of sustainable requirements (Rs) as well as improvement in requirement satisfaction in 3 teams (T3, T5 and T6); e.g. T6, produced no Rs without the tool in Session 1, but four Rs with the additional use of tool in Session 2; this reflected as an improvement in the increase in the number of requirements selected, but cannot be represented as a percentage increase in requirement satisfaction (as the R-G, which is the denominator, is zero).

- Besides the above three teams, the use of tool resulted, for two more (T1 and T4) teams, in increased sustainability considerations, i.e., increase in the number of sustainable requirements generated and selected. T4, for instance, generated only one Rs without the tool, but four with the addition of tool.

- Teams T1 and T4 also reflected significant improvement in the requirement satisfaction with the use of tool. For e.g. in T4, R-S without tool was one, but use of tool resulted in additional three $\mathrm{R}-\mathrm{S}$, therefore showing an increase in the selection of requirements to $300 \%$ of what was without tool. Similarly, in T1, a $66.7 \%$ increase in requirement selection was found, reflecting improvement in requirement satisfaction.

- In three teams (T4, T5 and T6), the use of the tool also resulted in an increase in the number of non-sustainability requirements generated (Rns-G), non-sustainability requirements selected (Rns-S) and an overall improvement in the requirement satisfaction. For e.g., T5 and T6 showed an increase in requirement selection by $20 \%$ and $33.3 \%$ respectively, while T4 showed a significant increase to $200 \%$.

- It is observed that T4 consistently performed well in satisfying requirement generated for both (Rs) and (Rns) without and later with the addition of the tool, while T2 refrained from putting the tool to use.

\subsection{Key findings and inferences}

- The additional use of tool was found to not only improve incorporation of sustainability considerations, i.e., increase in the generation of sustainable requirements (Rs-G) in 5 out of 6 teams, but also showed potential to improve requirement satisfaction with respect to sustainability of the design, through increase in the selection of sustainable requirements (R-S), as was seen in 5 out of 6 cases.

- The use of tool was also found to positively influence the increase in generation and selection of non-sustainable requirements in 3 out of 6 cases, thereby showing potential to holistically support requirement satisfaction.

- It was noted that with the use of the tool, though a greater number of 'sustainable requirements' (Rs) were generated, not all of these could be addressed by the designers in their solutions. The cause of lack of satisfaction of requirements through selection of sustainability requirements requires further investigation.

- With respect to requirement satisfaction alone, T4 showed exemplary performance with and without tool, indicating the influence of the design team in the overall creative performance.

- It was also interesting to note that $\mathrm{T} 2$ did not use the tool to reiterate the LoR and generate new requirements.

\section{SUMMARY AND DISCUSSIONS}

InDeaTe is a web-based, process guidance tool tested earlier for its support in imbibing lifecycle thinking into the design process and improving the sustainability of the eventual designs. It comprises a Process Template, and a Design Database that houses sustainability related information that are ontologically tagged to Activities, Criteria, Life cycle phase, Outcome, Design Stage and Structure. The increase in the number of requirements - an outcome of the design process - is indicative of the increase in the sustainability considerations. The aim of this collaborative research was to investigate the potential of InDeaTe in supporting 'requirement-satisfaction', thereby improving the usefulness aspect of 
creativity of a design. The impact of the tool in improving usefulness and harnessing sustainable design innovations was assessed via comparative studies across teams with varied cultural backgrounds.

A large number of design solution-outcomes, around $83 \%$ of the results, showed promise where both sustainability and innovation were supported by use of tool. However, there are instances where the creativity in the design and sustainability of the solution were not supported by the tool.

A possibility of poor (degree of) requirement-satisfaction, i.e., low percentage of requirement selection, in spite of generation of large number of sustainable requirements, might be the dearth of time to address the requirements selected or a lack of understanding of the nature of sustainability requirement to be addressed, or lack of means (methods and tools) with which to address these requirements.

It is also noted that the personality of the designers is a key factor in determining the creativity of the design or the creative problem-solving process.

\section{LIMITATIONS AND FUTURE WORK}

The study presented was limited to assessing 'usefulness,' which is only one of the major indicators of creativity; it is also important to support 'novelty' if creativity is to be supported holistically. Future work entails further development of the tool to support requirement-selection, and support requirement-satisfaction with the appropriate tools and methods including those for novelty. Another possible future direction would be to develop the tool interface, such that it persuades the disinterested designers to use it. The small number of teams available in the study is another limitation, which does not allow making strong inferences, another aspect to be addressed in the future.

\section{REFERENCES}

Acharya, S., Chatty, T., R, B.S.C., Ghadge, K., Bharath, P.A. and Chakrabarti, A. (2018), "InDeaTe 3.0: An Ontology based, generic design process guidance web-tool", Proceedings of 15th International Design Conference (DESIGN 2018) Dubrovnik, Croatia.

Acharya, S., Ghadge, K., Langfitt, Q.M., Pezeshki, C., Ameta, G., Rachuri, S. and Chakrabarti, A. (2017a), "Supporting sustainable product design: a case study with InDeaTe tool and template at Washington State University, Pullman, WA", Proceedings of the International Conference on Research into Design (ICoRD’17), Vol.2, Guwahati, India.

Acharya, S., Ghadge, K., Uchil, P., Flynn, C.D., Johnson, A.J., Squier, M.N., Yang, Y., Yang, X., Davidson, C.I., Ameta, G., Rachuri, S. and Chakrabarti, A. (2017b), "Supporting sustainable service-system design: a case study on green-roof design with InDeaTe template and tool at Syracuse, New York", Proceedings of the International Conference on Research into Design (ICoRD'17), Vol.2, Guwahati, India.

Bossel, H. (1999), Indicators for sustainable development: theory, method, applications, International Institute for Sustainable Development, Winnipeg, pp. 138.

Cavallucci, D. (2002), “TRIZ, the Altshullerian approach to solving innovation problems”, In: A. Chakrabarti, (Ed.), Engineering Design synthesis - understanding, approaches and tools, Springer Verlag, London, UK.

Chakrabarti, A., Acharya, S., B.S.C., R, Devadula, S., Ghadge, K., Madhusudhanan, N., Uchil, P., Srinivasan, V., Ameta, G. \& Rachuri, S., (2017), "InDeaTe-A Computer-Based Platform with a Systematic Design Template and a Database of Methods and Tools". In Proceedings of the International Conference on Research into Design (ICoRD’17), Vol.2, Guwahati, India

Devadula, S., Ghadge, K., Vishwanathan, S., Chan, S.H., Langfitt, Q.M., Dornfeld, D., Gupta, A., Rachuri, S., Ameta, G. and Chakrabarti, A. (2017), "Supporting social innovation: application of InDeate tool for sustainable service design — case study of community workshop", Proceedings of the International Conference on Research into Design (ICoRD'17), Vol.2, Guwahati, India.

Eder, W. (1995), "Introduction", Proceedings of the Workshop on Engineering Design and Creativity, Pilsen, Czech Republic, pp. 16-18.

Elkington, J. (1997), Cannibals with forks. The triple bottom line of 21st century

EPA, U. S. (1993), Life-Cycle Design Guidance Manual, US Environmental Protection Agency, Office of Research and Development, Washington DC.

Ghadge, K., Vishwanathan, S., Devadula, S., Langfitt, Q.M., Chan, S.H., Patel, A., Ameta, G., Gupta, A., Rachuri, S. and Chakrabarti, A. (2017a), "Application of InDeaTe design toolbox for designing sustainable products - case study of a natural water cooler", Proceedings of the International Conference on Research into Design (ICoRD’17), Vol.2, Guwahati, India. 
Ghadge, K., Vishwanathan, S., Devadula, S., Langfitt, Q.M., Chan, S.H., Ratnakar, G.K., Ameta, G., Gupta, A., Rachuri, S. and Chakrabarti, A. (2017b), "Application of InDeaTe design toolbox for designing sustainable manufacturing systems - case study of a micro-hydel turbine", Proceedings of the International Conference on Research into Design (ICoRD'17), Vol.2, Guwahati, India.

Howard, T.J., Culley, S.J. and Dekoninck, E. (2008), "Describing the creative design process by the integration of engineering design and cognitive psychology literature”, Design Studies, Vol. 29, pp. 160-180.

Kota, S. and Chakrabarti, A. (2014), “ACLODS: A holistic framework for product lifecycle design”, Intl. J. Product Development, Vol. 19 No. 1/2/4.

Lopez-Mesa, B., Mulet, E., Vidal, R. and Thompson, G. (2011), "Effects of additional stimuli on idea-finding in design teams", Journal of Engineering Design, Vol. 22, pp. 31-54.

Lozano, D.J. (2009), "Metodología para la eco-innovación en el diseño para desensamblado de productos industriales.

Moss Jr, J. (1966), "Measuring Creative Abilities in Junior High School Industrial Arts”, Monograph, Vol. 2.

Oman, S.K., Tumer, I.Y., Wood, K. and Seepersad, C. (2013), A comparison of creativity and innovation metrics and sample validation through in-class design projects, Research in Engineering Design, Vancouver.

Peeters, J., Verhaegen, P.A., Vandevenne, D. and Duflou, J.R. (Oct 2010), Refined metrics for measuring novelty in ideation, IDMME Virtual Concept Research in Interaction Design, pp. 20-22.

Ranjan, B.S.C., Siddharth, L. and Chakrabarti, A. (2018), “A systematic approach to assessing novelty, requirement satisfaction, and creativity", Artificial Intelligence for Engineering Design, Analysis and Manufacturing, Vol. 32, pp. 390-414.

Sarkar, P. and Chakrabarti, A. (2015), "Creativity: generic definition, tests, factors and methods", International Journal of Design Sciences \& Technology, Vol. 21 No. 1.

Sarkar, P. and Chakrabarti, A. (2011), "Assessing design creativity”, Design Studies, Vol. 32, pp. 348-383.

Sarkar, P. and Chakrabarti, A. (2007), "Development of a method for assessing design creativity", Proceedings of International Conference on Engineering Design (ICED07), Paris, France.

Schmidt, W. and Taylor, A. (2006), "Ford of Europe's product sustainability index", Proceedings of 13th CIRP International Conference on Life Cycle Engineering, Leuven, Belgium.

Shah, J., Smith, S. and Vargas-Hernandez, N. (2003), "Metrics for measuring ideation effectiveness", Journal of Design Studies, Vol. 24 No. 2, pp. 111-134.

Srinivasan, V. and Chakrabarti, A. (2010), “An integrated model of designing”, Journal of Computing and Information Science in Engineering, Vol. 10, pp. 031013.

Strange, T. and Bayley, A. (2008), Sustainable development: Linking economy, society, environment, OECD, Paris.

Sustainability Standards protocol, National Institute of standards and Technology (NIST), https://www.nist.gov/services-resources/software/sustainability-standards-portal-ssp

Uchil, P., Ghadge, K., Acharya, S., Bhinge, R., Robinson, S., Dornfeld, D., Rachuri, S., Ameta, G. and Chakrabarti, A. (2017), "Supporting manufacturing system design: a case study on application of InDeaTe design tool for a smart manufacturing system design”, Proceedings of the International Conference on Research into Design (ICoRD’17), Vol.2, Guwahati, India.

Vezzoli, C. and Manzini, E. (2008), Design for Environmental Sustainability, Springer-Verlag London Limited.

WCED, U. (1987), Our Common Future-The Brundtland Report, Report of the World Commission on Environment and Development.

\section{ACKNOWLEDGMENTS}

Acknowledgements to Indo-US Science and Technology Forum (IUSSTF) and JASSO Scholarship (JAIST) for much appreciated financial support, and our sincere gratitude to all the participants of the design study at JAIST. 
